\title{
Ambientes organizacional e informacional da Cadeia Produtiva de Café
}

\author{
Lucileide Andrade de Lima do Nascimento \\ lucileidelima@gmail.com \\ Universidade Federal do Espírito Santo, Departamento de Biblioteconomia, Vitória, ES, Brasil \\ Emir José Suaiden \\ emir@unb.br \\ Universidade de Brasília, Faculdade de Ciencia da Informação, Brasília, DF, Brasil
}

Resumo: Analisa o ambiente e fluxos de informação na Cadeia Produtiva de Café (ES). Parte do seguinte problema: Como se configuram o ambiente informacional e os respectivos fluxos de informação entre os agentes que compõem a Cadeia Produtiva de Café (ES)? Apresenta breve histórico sobre a emergência da cafeicultura capixaba e sequente conformação da cadeia produtiva. Analisa, nesta etapa de pesquisa, a configuração dos ambientes organizacional, institucional, informacional e discute as possibilidades de pesquisa de respectivos fluxos de informação na relação entre os agentes que compõem a Cadeia Produtiva de Café (ES). Discute aspectos das inter-relações entre território, cadeia produtiva e informação identificando as conexões entre informação e território. Conclui que, sob a perspectiva do território, a questão informacional assume sua matiz social na relação entre território e cadeia produtiva visto que, tanto a informação, quanto o conhecimento já acumulados e instrumentalizados pela cadeia produtiva relativos à cafeicultura estão enraizados no território, foram produzidos, organizados e processados entre atores locais, a partir de práticas informacionais e relações sociais instituídas na dinâmica desse território - significando dizer que existe um tipo de informação específica e que determina o valor da informação sobre o café para o território capixaba, neste caso estudado.

Palavras-chave: Ambientes de Informação; Cadeia Produtiva de Café (ES) - Brasil; Cafeicultura - Espírito Santo (Brasil). Fluxos de Informação; Território e informação.

Organizational and informational environments of the productive chain of coffee (Espirito Santo, Brazil)

Abstract: Analyzes the environment and information flows in the Productive Chain of Coffee (ES). It comes from the following problem: How to configure the information environment and their information flows among agents that compose the Productive Chain of Coffee (ES). Presents brief history about emergence of capixaba coffee culture and follow conformation up of the productive chain. It analyzes in this research step, the configuration of organizational, institutional, informational environments and discusses the research possibilities of their information flows in the relationship between the agents that make up the Productive Chain of Coffee (ES). It discusses aspects of the interrelationships between territory, productive chain and information identifying the connections between information and territory. It concludes that, from the perspective of the territory, the informational question assumes its social tone in the relationship between territory and productive chain since both the information and the knowledge already accumulated and exploited by the productive chain related to coffee production are rooted in the territory, were produced, organized and processed between local actors, from information practices and social relations imposed on the dynamics of this territory - meaning to say that there is a kind of specific information that determines the value of information about coffee for the state of Espírito Santo, in this case study.

Keywords: Coffee Culture - Espírito Santo (ES) - Brazil; Information environments; Information Flow; Productive Chain Coffee (ES) - Brazil; Territory and Information. 
Resumen: En el presente trabajo, se analiza el medio ambiente y los flujos de información en la cadena de Producción de Café en E.S, Brasil. Parte del siguiente problema: ¿Cómo se conforma el ambiente informacional y los respectivos flujos de información, entre los agentes que componen la cadena productiva de Café en E.S? Para comenzar, es presentada una breve historia de la caficultura capixaba, hasta la conformación de la cadena de producción. En esta etapa de investigación, es analizada la disposición de los ambientes organizacionales, institucionales e informacionales, se discute las posibilidades de investigación de los respectivos flujos de información y la relación entre los agentes que componen la Cadena Productiva de Café en E.S. Se discuten aspectos de las interrelaciones entre territorio, cadena productiva e información, identificando las conexiones entre información y territorio. Como conclusión, desde la perspectiva de territorio, la cuestión informacional asume un matiz social, en la relación entre territorio y cadena productiva, dado que, tanto la información así como el conocimiento ya acumulados e instrumentalizados por la cadena productiva, en relación a la caficultura, están enraizados en el territorio, fueron producidos, organizados y procesados entre actores locales, a partir de prácticas informacionales y relaciones sociales, instituidas en la dinámica de ese territorio, lo que significa que hay un tipo de información específica que determina el valor de la información sobre el café para la provincia de Espirito Santo (Brasil)

Palabras-clave: Ambientes de información; Cadena de Producción de Café; Caficultura - Espirito Santo (Brasil); Espirito Santo (Brasil); Flujos de información. 


\section{Introdução}

O estudo da Cadeia produtiva de Café no Estado do Espírito Santo (ES) e sua ambiência apresenta-se como um relevante indicador para formulação de políticas de informação para o território capixaba ${ }^{1}$ dada a sua alta inserção na dinâmica social do Espírito Santo (ES), uma presença definidora de arcabouços sociais de transferência de informação representativos do território no qual interage e se sustenta. A Cadeia Produtiva de Café (ES) encontra-se inserida na vida social do capixaba com alto grau de capilaridade, presente em 65 dos 78 municípios capixabas, assumindo um papel descentralizador com expressiva contribuição para melhor distribuição espacial de renda dos municípios que dela fazem parte (VILASCHI FILHO; FELIPE, 2010).

Neste recorte analisado o aspecto inovador dessa pesquisa remete à área temática: o ambiente informacional (de alta capilaridade e nível de inserção social) e respectivas interações, que circundam essa cadeia produtiva. Os ambientes econômico, social, cultural e institucional influenciam a natureza e a intensidade em que ocorrem as interações entre os atores, sejam ligados à cadeia produtiva ou aos municípios (agentes e organizações) com os quais interage. Do ponto de vista da cadeia produtiva, considerando as estratégias de mercado, esta interação é de alta relevância, pois a partir dela são produzidas as diversas formas de aprendizado necessárias ao processo de tomada de decisão, prospeç̧ão, inovação e desenvolvimento das capacitações de ordem produtiva, tecnológica e organizacional, ou seja, definem o grau de aprofundamento que propicia a produção de conhecimento tácito ou da vantagem competitiva no mercado.

Por outro lado, do ponto de vista da gestão municipal, a caracterização do ambiente e de respectivos fluxos de informação no processo de interação significam subsídios chave para o processo de governança dessas localidades. Em observação à vasta literatura produzida sobre a cafeicultura capixaba identificamos que a dimensão informacional encontra-se indiciada como um elemento chave, mesmo porque as discussões emergentes sobre arranjos produtivos ou cadeias produtivas operam com base na centralidade do conhecimento orientado à pesquisa, inovação e desenvolvimento (economia do conhecimento e do aprendizado), mas objetivamente não identificamos estudo especificamente tratando dessa perspectiva de análise para o caso capixaba específico. A pesquisa da Cadeia Produtiva de Café (ES) na

\footnotetext{
${ }^{1} \mathrm{O}$ termo capixaba (de origem na língua indígena tupi) é uma nomeação aplicada, na atualidade, aos nascidos no Estado do Espírito Santo.
} 
perspectiva eminentemente informacional nos pareceu um aspecto praticamente inexplorado, apesar de indiciado quanto à sua necessidade de análise.

Neste artigo demonstramos os principais aspectos analisados, até o presente momento, a partir de dados secundários já sistematizados e publicados nas fontes arroladas e que envolvem temas ligados ao território, ambientes organizacional, institucional e informacional da Cadeia produtiva de Café (ES) e do mercado de café brasileiro.

\section{Ambiente Organizacional da Cadeia Produtiva de Café (ES) Como Espaço de Interação}

Ambientes organizacionais, de forma geral, compõem-se de infraestrutura, pessoas e tecnologias em dois espaços de interação: o ambiente externo ou macro e o ambiente interno ou micro. O ambiente externo abarca o contexto de interação da organização que pode influenciar ou interferir na gestão dos processos organizacionais. O ambiente interno se relaciona com os processos organizacionais, de infraestrutura, de tecnologia, de produtos, serviços e relacionamentos que a organização mantém em sua dinâmica produtiva (VALENTIM, 2010). Os espaços de interação também podem se referir, além dos ambientes (interno e externo), a situações ou momentos, em dado espaço-tempo, facilitadores para os processos de geração, difusão e uso de informação entre sujeitos, grupos de trabalho, organizações. Produzem níveis de interação formais, informais, presenciais, virtuais, permanentes ou temporários (BALESTRIN; VERSCHOORE, 2008). O desenvolvimento organizacional ocorre por força do papel da informação na gestão dos processos, a informação é intrínseca a quase tudo que a organização faz $(\mathrm{CHOO}, 2006)$, assim pode-se dizer que as ações organizacionais nesses espaços produzem o ambiente informacional e os fluxos de informação (VALENTIM, 2010).

Os ambientes social, político e econômico estabelecidos pela cafeicultura capixaba foram preponderantes para a definição e melhoria da dinâmica de desenvolvimento e minimização das carências regionais típicas do Estado desde o período colonial. Para melhor compreensão dos fatos, dinâmica relacional dos processos econômicos, sociais e políticos fazse necessário reconhecer e pensar as mudanças, movimentos e vínculos que gradualmente se estabeleceram nas instituições ou em sua sociabilidade. As circunstâncias históricas pavimentam o percurso: “[...] a mudança é constrangida pela dependência da trajetória [...]" (SILVA, 2010, p. 35).

$\mathrm{Na}$ evolutiva da cafeicultura até a sua conformação em uma cadeia produtiva-alguns fatos históricos se destacaram: o pioneirismo da atividade e vocação dos cafeicultores, as bases tecnológicas e institucionais de sustentação da cafeicultura, nível de interação da cadeia 
produtiva, grau de inserção político-social e o nível de sustentabilidade econômica (SILVA et al., 2007; VILLASCHI FILHO; FELIPE, 2010).

A história do Estado do Espírito Santo (ES) está profundamente marcada pela dinâmica cafeeira em seu território. Destaca-se no cenário nacional como o segundo maior produtor de café, o maior produtor da espécie conilon cobrindo cerca de $76 \%$ da produção nacional, e o terceiro maior produtor da espécie arábica (com $10 \%$ da produção total no país). 0 modelo produtivo é de base familiar (73\%) operando em cerca de 60 mil propriedades, com 131 mil famílias envolvidas somente no processo produtivo que, no conjunto, articula uma rede geradora de aproximadamente 400 mil postos de trabalho ao ano respondendo por $43 \%$ do valor bruto da produção agrícola capixaba (CAFEICULTURA, 2012; CONAB, 2014).

O cenário atual da Cadeia Produtiva de Café (ES) está caracterizado por uma rede institucionalizada de atores em diversos contextos de interação e etapas de produção: desde o produtor até consórcios, cooperativas, empresas inovadoras, governos locais, institutos de pesquisa, instituições ligadas ao ensino e de financiamento dentre outras (SILVA et al., 2007; VILLASCHI FILHO; FELIPE, 2010). O desafio que se coloca é compreender a capacidade de ação dessa rede institucionalizada em manter-se coerente e a um nível de conectividade (que propicie comunicação rápida e eficaz) para estabelecer-se como uma rede de cooperação orientada à criação, comunicação e utilização de informação, visto que os espaços de interação podem transformar-se em plataformas para a produção de informação e de conhecimento junto às organizações (BALESTRIN; VERSCHOORE, 2008).

No caso específico do ambiente organizacional da variedade conilon junto à Cadeia Produtiva de Cultivo de Café (ES), os espaços de interação já instituídos estão orientados ao fortalecimento de três bases dinâmicas sustentadoras da cadeia produtiva: tecnológica, metodológica e institucional (SILVA et al., 2007). Os espaços estão distribuídos como eixos de ações desenvolvidos para fomento dessas bases principalmente estimulados e organizados pelo Incaper, Cetcaf, universidade e cooperativas.

Na base tecnológica as estratégias de ações estão dirigidas aos jardins clonais, viveiros de mudas e fazendas experimentais do Incaper utilizados como recurso de difusão (ambiente de visitas técnicas, formação e reconhecimento de variedades, demonstração de técnicas e tecnologias, palestras, cursos, encontros, dias de campo, visitas às fazendas experimentais) e transferência de tecnologias (produção e distribuição de mudas e estacas, publicações técnicas, subsidio às atividades de extensão rural). Os jardins clonais e viveiros viabilizam o rápido acesso dos cafeicultores às variedades de café melhoradas pelo Incaper, são 190 jardins clonais distribuídos em 50 municípios com capacidade produtiva de 50 milhões de mudas por 
ano (FONSECA et al., 2007). Atendem principalmente às prefeituras, associações de produtores, cooperativas, centros de pesquisa, escolas agrotécnicas e viveiristas. Os resultados obtidos estão orientados ao melhoramento genético de biotecnologia, fitotecnia e fisiologia, também à implantação e manejo da cultura, adubação e calagem, fitopatologia, entomologia, irrigação, sistema de informação agrometeorológico para monitoramento do clima, instalação de jardins clonais, viveiros de mudas e melhoria na qualidade final do produto.

Na base metodológica os esforços para promoção de interação objetivam motivar, informar e transferir tecnologias aos produtores, de forma individual, coletiva e ampliada, realizada principalmente pelas instituições vinculadas ao governo de Estado ou federal em parceria com as entidades afins que compõem a cadeia produtiva. As estratégias estão classificadas em quatro grupos: assistência ao produtor, incentivos a articulação e formulação de fóruns e redes de cooperação, campanhas e unidades demonstrativas e de observação. A assistência ao produtor constitui-se como uma atividade extensionista que oferece cursos, demonstrações de métodos e boas práticas, dias-de-campo, dias especiais, excursões de produtores e concursos de produtividade. Os incentivos a articulação e formulação de fóruns $e$ redes de cooperação são realizados a partir de uma agenda de eventos de teor técnico, informativo e de intercâmbio como simpósios, palestras, entre outros. As campanhas são utilizadas pelos profissionais extensionistas envolvendo a articulação de vários métodos objetivando o estímulo ao desenvolvimento de práticas desejáveis e necessárias à qualificação do processo produtivo, a padronização de boas práticas e cultivo e manejo da lavoura. Exige uma estrutura bem montada de canais comunicativos e informativos para a ocorrência de sincronia e disseminação dos objetivos, a produção de publicações técnicas para subsidiar os procedimentos a serem alcançados, como por exemplo, campanha de poda de café, controle de pragas, dentre outros (SILVA et al., 2007).

$\mathrm{Na}$ base institucional o foco orientou-se para a formação de parcerias e alianças objetivando a produção de um arranjo institucional para a produção de conhecimento e consequentes processos de inovação para melhoria da competitividade da cadeia produtiva. Além dos interesses envolvidos, a aproximação geográfica facilitou a criação de um ambiente de cooperação para alcance das metas. Os grupos envolvidos podem ser assim classificados: agentes públicos, cooperativas, federações, sindicatos, agentes privados, organizações nãogovernamentais, Centro de Desenvolvimento Tecnológico do Café e bancos.

Estas institucionalidades caracterizam uma cadeia produtiva em franca expansão com avanços significativos nas redes de cooperação instituídas e em fase de compartilhamento das experiências com outras cadeias ou arranjos produtivos locais (APL). 


\subsection{O Arranjo Institucional}

As primeiras ações de articulação do arranjo institucional da Cadeia Produtiva de Cultivo de Café (ES) podem ser datadas a partir da década de 1980 impulsionadas por ações decisivas de pesquisa promovidas pelo antigo Instituto Brasileiro do Café (IBC), pela Empresa de Assistência Técnica e Extensão Rural (Emater-ES), pela Empresa Capixaba de Pesquisa Agropecuária (Emcapa). Posteriormente o Instituto Capixaba de Pesquisa, Assistência Técnica Extensão Rural (Incaper), a partir do ano de 2000 tem dado solução de continuidade às ações de pesquisa, assistência técnica e extensão rural. Essa articulação entre pesquisa, financiamento e incentivos de natureza pública definiram as bases sobre as quais foram estruturados os arranjos institucionais da Cadeia Produtiva de Café (ES).

Após uma conjuntura conturbada de quase três décadas de oscilações decorrentes da política nacional de erradicação dos cafezais na década de 1960, de segunda erradicação por causa de pragas, do plano de emergência para a crise instalada, do plano de renovação dos cafezais e incentivos de expansão na década de 1970. Uma série sistemática de crises em um cenário político no estado adverso, marcado por desmandos do governo, má utilização dos recursos públicos, ausência de políticas estruturais para a agricultura além de retrocessos na gestão administrativa da região. No cenário nacional o movimento era de convergência da estrutura agrícola, de base familiar de pequeno porte, para padrões técnicos facilitadores à aproximação da indústria, cujo interesse dirigia-se para as atividades ligadas a agricultura de grande porte ou de exportação, relegando a agricultura familiar, de pequena produção (ROCHA; MORANDI, 1991).

Ao início da década de 1980 a cafeicultura capixaba encontrava-se em processo de maturação, decorrente dos financiamentos e apoio creditício oferecido pelo governo para diversificar a agricultura, cujo rescaldo serviu para impulsionar o aumento da produção em $80 \%$ e de sua expansão em $50 \%$. O modelo de produção através da agricultura familiar e/ou sistema de parcerias foi mantido, mas também foi incentivada a expansão de empresas rurais, modeladas sob a lógica capitalista do trabalho assalariado e produção em escala. Nessa nova cafeicultura a tecnologia foi instrumentalizada como o seu maior insumo, incorporando maquinário e técnicas de produção, cultivo e beneficiamento do produto - um novo modelo sustentado pela tecnificação agrícola (ROCHA; MORANDI, 1991). Os esforços na década de 1980 para qualificar a base tecnológica e ampliar o avanço da cafeicultura produziram um ambiente e infraestrutura favorável à organização de atividades institucionalizadas para a gestão técnica, evolução e expansão desse circuito produtivo. 
Na década de 1990 várias ações de iniciativa estadual propiciaram a maturação organizacional da cadeia produtiva. Considerando os registros históricos, essa década de 1990 constituiu-se como um período de consolidação das instituições e institucionalidades (um ambiente regulatório) no arranjo estrutural da cadeia produtiva: o Estado como principal agente formulador e financiador das políticas se mobilizou rumo ao estabelecimento de bases mais estáveis para o processo evolutivo da cafeicultura. Tal mobilização estimulou o surgimento da Câmara Setorial do Café como espaço de formulação de políticas, do Centro de Desenvolvimento Tecnológico do Café (CETCAF) para atuar como um agente articulador e mediador entre os setores público e privado. Também foram organizados diversos eventos e produzidas publicações técnico-científicas como estratégias de sistematização, nivelamento e socialização do conhecimento até então produzido, campanhas de poda para alcance de maior produtividade e revigoramento das lavouras e o Zoneamento Agroecológico para a Cultura do Café. Esse estudo foi basilar para definições futuras relativas à implantação de lavouras para o café conilon no Estado (SILVA et al., 2007).

Ao início dos anos de 2000, a cafeicultura capixaba encontrava-se em um ambiente favorável de estabilidade quanto a organização produtiva, arranjo institucional, progresso tecnológico e grau de inserção na dinâmica nacional de pesquisa nesse campo. Silva et al. (2007) relacionam um conjunto de ações realizadas, de amplo alcance, que gradativamente favoreceu a dinâmica reprodutiva da cadeia produtiva de café. Essas ações propiciaram o contínuo e sistemático avanço da cadeia produtiva.

$\mathrm{Na}$ atualidade a situação institucional da Cadeia Produtiva de Café (ES), considerando os dados até aqui levantados, revela características já diagnosticadas como presentes na lógica mercadológica desses ambientes: as regulações naturais do mercado não se apresentam suficientes para garantir uma coordenação eficiente desse sistema, o papel do Estado como articulador e fomentador de pesquisa tem sido preponderante para a evolução da cafeicultura. Segundo Zylbersztajn (1995) esta conclusão pode ser aplicada à cafeicultura no Brasil que também apresenta acentuada necessidade de coordenação vertical e cada vez mais baseada em informação porque se apresenta como um fenômeno intrínseco a quase todas as funções desempenhadas pelas organizações (CHOO, 2006).

A análise da literatura produzida por especialistas que atuam junto à dinâmica reprodutiva da cadeia aponta que também persistem muitos desafios em relação à melhoria da competitividade. Um desses desafios refere-se às dificuldades de mecanização da etapa de colheita das lavouras cafeeiras cultivadas em regiões de montanha. Dados apresentados por Aguiar (2010) por ocasião da pesquisa indicam que, cerca de $90 \%$ do café produzido no Estado 
do ES ainda era colhido manualmente respondendo por $50 \%$ dos custos de produção. Apesar da cafeicultura capixaba desenvolver, já por alguns anos, a tecnologia de poda programada para os tipos conilon e arábica, permitindo melhores rendimentos no processo de colheita como aumento de produtividade em até $35 \%$ e a redução da mão de obra em até $50 \%$, no caso do arábica (SILVESTRE, 2014). Recente balanço de atividades divulgado pelo Incaper tratando do impacto econômico das ações (tecnológicas e sociais) desenvolvidas nos últimos anos apontam para um incremento de produtividade superior a 7 bilhões na cadeia produtiva de café (OLIVEIRA; BORGES, 2014).

Num cenário global, incluída a cadeia capixaba, ainda persiste o enfoque de investimentos em pesquisa (P\&D) muito orientados aos processos de produção e pouco afinados aos problemas relativos à cadeia do produto até o seu consumo (ZYLBERSZTAJN, 1993). De forma complementar Monte (2012) sugere ainda que, para alavancar a qualidade do café devem ocorrer avanços na propaganda do café capixaba (cafés estaduais) e brasileiro no mercado internacional objetivando elevar o consumo do café nacional e capixaba nesse mercado internacional.

\section{Conceituações Sobre Ambiente Informacional e Fluxos de Informação}

O ambiente informacional, no contexto desta pesquisa, compõe a estrutura sociocultural existente nos espaços de interação da cadeia produtiva, compõe no tecido social o conjunto de práticas político-discursivas, serviços, recursos, regras e normas relativas ao manejo e produção do Café e os espaços que permitem a interação entre os atores, a produção de tecnologia, o compartilhamento de informações definindo o arranjo institucional dessa cadeia produtiva.

A análise do ambiente informacional e respectivos fluxos de informação na Cadeia Produtiva de Cultivo de Café (ES) propiciam a produção de indicadores e o reconhecimento de fatos da realidade que podem contribuir para a sua sustentação e desenvolvimento. Por natureza, os ambientes organizacionais impõem tipologias diversificadas de ambientes informacionais em que circulam os conteúdos que integram os saberes e fazeres das institucionalidades que compõem a cadeia produtiva (VALENTIM, 2010). A informação é geralmente percebida como um elemento natural a todas as processualidades humanas (ALBAGLI; MACIEL, 2004) e tem sido caracterizada como um operador de relação justamente porque, toda ação tem origem na informação.

Os fluxos de informação se manifestam como resultado das interações formalizadas e sistematizadas dos sujeitos (constituem as ações organizacionais) são influenciados pela 
estrutura organizacional, pelas condições ambientais (internas e externas) e dependendo da cultura organizacional estabelecida tendem a ser mais, ou, menos uniformes. Podem ser categorizados como formais (ou estruturados) e informais (ou não-estruturados). Os fluxos formais ou estruturados têm visibilidade, se caracterizam como produto das atividades sistematicamente desenvolvidas, são apoiados por normas e procedimentos, são registrados sob inúmeros suportes (papel, digital), circulam em meios e ambientes diversificados (correios, intranet, internet). Os fluxos informais ou não estruturados se caracterizam por sua invisibilidade, são resultantes das vivências e experiências dos sujeitos que atuam nas organizações. São de difícil reconhecimento e gestão, pois exigem uma cultura organizacional que propicie a sua ação efetiva, como enfatizado por Valentim (2010).

As características interdisciplinares e transdisciplinares que definem o objeto informação propiciam as condições de desvelamento dos ambientes, fenômenos e dos próprios fluxos informacionais inerentes aos saberes e fazeres dos territórios e da Cadeia Produtiva. Nestes termos pesquisar os fluxos de informação significa buscar a essência dos processos de organização do conhecimento. A caracterização das condições de produção, circulação e uso da informação significa também a possibilidade de observar como tais condições se relacionam com as formas de apropriação social (informação como bem público) e formas de apropriação privada (informação como mercadoria).

As estratégias de gestão nas organizações na atualidade reconhecem a necessidade de informação para criar significados, construir conhecimento e tomar decisões. O reconhecimento do papel estratégico da informação possibilita a sua instrumentalização para dar sentido às mudanças que ocorrem no ambiente externo, reconhecendo também que esse ambiente influencia e define os padrões de competitividade e de vantagem a serem obtidos justamente pelo seu melhor controle. Do ponto de vista da organização produtiva a construção de conhecimento começa pela criação, organização e processamento da informação objetivando o desenvolvimento de capacidades, produtos, serviços, melhoria de recursos e processos propiciando, por conseguinte, a definição de diferenciais no modo de produção. 0 uso estratégico da informação é relevante para a tomada de decisões que, por sua natureza, exigem um nível de racionalidade para interpretar os fatos e fatores conjunturais ligados ao ambiente, processos e recursos que interferem e podem definir os resultados (favoráveis ou não) para a organização (CHOO, 2006). 
40 ambiente informacional e respectivos fluxos de informação no mercado de café brasileiro

A informação que circula no mercado agrícola brasileiro, em traços gerais, apresentase abundante e assimétrico, no tempo e no espaço entre os vários segmentos de mercado. Em um mercado de peso, intenso e influente como o mercado de café o volume de informações e fluxos que as conduzem também o são sob centenas de fontes de informação. A dificuldade estrutural remete às condições de assimilação dessas informações pelos agentes nesse mercado, dado também o seu excesso e assimetria (REZENDE; ROSADO, 2003).

Tal excedente de informações mobiliza esses agentes a continuamente elaborarem modelos mentais na tentativa de selecionar e assimilar as informações para, segundo North (1994), decifrarem a conjuntura no ambiente externo das organizações. Nesse mercado agrícola, incluído o mercado de café, a informação que circula tem se estruturado historicamente como um serviço provido principalmente pelo Estado porque custa caro e exige condições de produção que envolvem atributos de valor a serem aplicados à informação que é produzida. O papel do Estado provedor, na atualidade ainda define os níveis de atuação, os programas instituídos, a disponibilização, uso e regulamentação dessa informação para minimizar os efeitos do mercado imperfeito (decorrente do oportunismo, omissão e logro de parte dos agentes que nele agem) e dos desvios de eficiência decorrentes das informações incompletas ou imperfeitas que circulam, do poder de mercado e das externalidades que afetam a dinâmica reprodutiva desse setor.

O ambiente informacional do mercado de café brasileiro está composto de serviços de informação oferecidos pelo mercado, instituições, governos, agentes privados, dentre outros. O tipo de informação varia dependendo dos prazos (curto, médio e longo) para tomada de decisões (REZENDE; ROSADO, 2003).

As informações de curto prazo têm origem e cobrem aspectos demandados relativos a: onde, quanto e como comprar ou vender um produto. São informações correntes sobre: preços, ofertas, estoques e condições específicas de mercado. São coletadas e rapidamente disponibilizadas aos usuários. Referem-se ao movimento e às condições de mercado com o objetivo de subsidiar a tomada de decisão de produtores e intermediários quanto às oportunidades e as melhores condições de compra e venda. As cotações na bolsa de valores são úteis para apoiar as decisões recorrentes e minimizar os riscos de perdas, mas estudo realizado por Rezende e Rosado (2003) indicou que esta fonte de informação ainda se encontra subutilizada pela maioria dos agentes que compõem esse mercado. 
As informações de médio e longo prazo decorrem principalmente das informações correntes (de curto prazo) acumuladas, propiciando a produção de informações analíticas sobre evolução de preços, volume de compras e vendas, quantidade e qualidade e tipologias de produtos mais demandados. Tais informações servem de base para a projeção de tendências para esse mercado. Têm como foco os produtores, empresários, governo, consumidores e estruturam-se nas características de produção, preço, demanda e níveis de comercialização, seja no presente e no futuro, para a previsão de safras, por exemplo. Segundo Rezende e Rosado (2003) os riscos de uso desses conjuntos de informações têm relação com as metodologias utilizadas e acrescentamos, também têm relação com a direção ideológica e interesses de quem as produz.

Informações bem assimiladas podem definir significativos ganhos e melhorias na posição competitiva das organizações. O contexto sociopolítico atual exige das organizações alto grau de flexibilidade e adaptabilidade no seu processo de gestão para enfrentar as forças que influenciam os negócios. Estas forças surgem do ambiente externo e interno. No ambiente externo os fatores mais influentes são de ordem social, tecnológica, econômica, legal, comercial e cultural, dentre outros. No ambiente interno interferem fatores de natureza organizacional ligados ao marketing, finanças, pessoal e de produção (REZENDE; ROSADO, 2003).

Os resultados de pesquisa realizada por Rezende e Rosado (2003) para avaliar o sistema de informação de preço, safra e seus impactos sobre a cadeia produtiva de café no Brasil identificaram que, especificamente tratando dos fluxos de comercialização no mercado interno de café, a comunicação entre agentes e instituições tendia a ser dispersa, competitiva e com pouca ou nenhuma coordenação verticalizada no fluxo de informações objetivando a integração e desenvolvimento desse agronegócio. Analisando a comercialização objetivando o mercado internacional os resultados indicaram tendência a menor dispersão, maior competitividade, além de apresentar melhores níveis de coordenação verticalizada no fluxo de informações para alcançar padrão de qualidade mais uniforme no produto comercializado. Sobre os preços de café a pesquisa evidenciou que as cotações de preços de café disponibilizadas pelas instituições não apresentavam terminologia comum, utilizavam uma diversidade significativa de linguagens e modos de apresentar as cotações, além de evidenciar níveis de imprecisão nos dados apresentados. Acrescentam os autores que, estes resultados quando relacionados ao excessivo número de fontes de informação disponíveis e ao perfil dos usuários se tornam "[...] em sua maior parte, inócuas, uma vez que a universalidade de compreensão não foi implementada ou estabelecida" (REZENDE; ROSADO, 2003, p. 16). 
A análise das principais fontes de informação utilizadas por produtores, corretores, torrefadores e exportadores indicou que estes agentes, na ocasião da pesquisa, não dispunham de informação suficiente sobre classes e padrões de cafés especiais, pouco conheciam dos padrões tradicionais de classificação oficial dos cafés, faziam pouco uso de fontes eletrônicas e/ou digitais de informação, como a internet, além de não utilizarem os dados das bolsas de valores para acompanhar as cotações de preços e monitorar as oscilações do mercado (REZENDE; ROSADO, 2003).

Os cafeicultores, segundo a pesquisa em questão, apresentavam pouca capacidade de transformar os sinais e informações de mercado em informação útil para subsidiar as decisões durante a comercialização do café. Sinais evidentes dos altos níveis de assimetria de informação entre os agentes desse mercado (REZENDE; ROSADO, 2003).

Esse breve conjunto de problemáticas evidenciado sobre a informação que circula no mercado de café aponta para os desafios de ampliar e gerar fluxos de informação com maior equidade em sua produção, organização e disseminação ao longo da cadeia, desde o produtor até o consumidor.

\section{Considerações Finais}

Cada vez mais instituições reguladoras e coordenadoras de políticas e ações de mercado, como o Banco Mundial e a Organização Mundial do Comércio têm colocado como condição de desenvolvimento dos mercados a codificação e institucionalização dos ciclos sociais da informação, significando que a dimensão intangível dos recursos de informação requerem ambientes contratuais formalizados que "[...] explicitem a regulamentação dos ciclos sociais e econômicos da informação" (GONZALEZ DE GOMEZ, 1999, p.14). O desafio para a cadeia produtiva refere-se à manutenção da consistência entre as lógicas institucionais que a regulam e as lógicas do mercado, havendo na correlação de interesses a busca por "[...] formas inovadoras e inclusivas [...]" de institucionalização da informação (GONZALEZ DE GOMEZ, 1999, p.14). Sob o enfoque do mercado busca-se as formas inovadoras pela via tecnológica como estratégia de ampliação do poder da informação e do conhecimento. Sob o enfoque do território que abriga a cadeia produtiva, os contextos sociais das ações de informação buscam as formas inclusivas como condição distributiva do poder da informação e do conhecimento.

Sob a perspectiva do território a questão informacional assume sua matiz social na relação entre território e cadeia produtiva visto que, tanto a informação, quanto o conhecimento já acumulados e instrumentalizados pela cadeia produtiva relativos à cafeicultura estão enraizados no território, foram produzidos, organizados e processados entre 
atores locais, a partir de práticas informacionais e relações sociais instituídas na dinâmica desse território - significando dizer que existe um tipo de informação específica e que determina o valor da informação sobre o café para o território capixaba, (CARVALHO, 2009). "A circulação de conhecimento e seus processos de conversão, de tácito para explicito e vice-versa, envolvem processos de territorialização e de desterritorialização, processos de aprendizado e de sedimentação/enraizamento do conhecimento no território" (CARVALHO, 2009, p. 219). Na expressão de Santos (1994, p. 21): "Alguns lugares tendem a tornar-se especializados, no campo como na cidade, e essa especialização se deve mais às condições técnicas e sociais que aos recursos naturais. O papel da informação é crucial" (SANTOS, 1994, p. 21). Tanto as organizações produtivas que operam sob a lógica do mercado, como também, as organizações que ambientam a reprodução social da cadeia produtiva extraem significados e insumos da informação que é produzida, sejam sob a ótica da informação como mercadoria ou sob a noção de informação como bem comum orientado ao território que acolhe a cadeia produtiva estudada.

A noção de um regime de informação propicia a perspectiva para tratar aspectos tão amplos do fenômeno informação. Entendemos que regime de informação remete ao modo como a informação é predominantemente produzida em determinada formação social ou contexto. Esse modo de produção define os sujeitos, os papéis atribuídos, as organizações, as regras, os meios e recursos preferenciais, os padrões, os modelos e práticas de interação e distribuição e as autoridades informacionais. Conforme descrito por González de Gómez (1999, p. 27) um regime de informação

[...] desdobra-se, logo, num conjunto de redes formais e informais nas quais as informações são geradas, organizadas e transferidas de diferentes produtores, através de muitos e diversos meios, canais e organizações a diferentes destinatários ou receptores de informação, sejam estes usuários específicos ou públicos amplos.

Tal noção constitui um ambiente informacional apto a discutir aspectos políticos e de poder no manejo da informação para além dos limites do Estado como provedor alcançando a complexidade e baixa transparência típica decorrente dos conflitos, jogos de interesse, vontades díspares, efeitos adversos oriundos das dinâmicas globalizantes e de trato tecnológico. As organizações contemporâneas têm atuado com mais autonomia, menos vinculadas às grandes interpretações institucionais por conta das mudanças na gestão do Estado sobre as políticas e principalmente sobre as políticas de informação (GONZÁLEZ DE GÓMEZ, 1999). 
Na dinâmica tradicional o Estado provedor agia como um observador privilegiado no papel de unificador, integrador de políticas e fluxos de informação definindo regras, normas, formatos padronizados, metrologia sob uma visão sistêmica. De forma distinta, a dinâmica social atual opera sob duas forças prevalentes: a globalização e a democratização, obrigando a revisão de práticas, implicando no reconhecimento de que a centralidade da interação entre governo e atores fora do governo está orientada para os processos de comunicação e tomada de decisão de forma mais coletiva.

A interação, nessa dinâmica de governance, não está dirigida pelo uso do Estado (poder e autoridade), mas pela capacidade de lidar/conduzir um complexo conjunto de ferramentas de governo (hardware e software), de negociação e pela rede de relacionamentos que reflete a dinâmica de poder entre os atores para construir práticas de tomada de decisão mais coletivas (CHHOTRAY; STOKER, 2009).

Diante desse quadro a análise do ambiente informacional implica na observação da autonomia dos atores sociais que sustentam a cadeia produtiva em suas possibilidades de realizar práticas ou ações diferenciais de informação. O foco nas redes de cooperação ou de interação permite uma aproximação para reconhecimento das capacidades de escolha/seleção das relações e níveis de interação sejam sociais, cognitivos e principalmente informacionais. Nestes termos a pesquisa em andamento objetiva analisar, em etapa futura, o processo de produção, circulação, transferência e uso de informação na dinâmica relacional da Cadeia Produtiva de Cultivo de Café (ES) para diagnosticar as condições sociais de produção e enunciação da informação e também para caracterizar as condições sociais de recepção e uso de informação nessa dinâmica relacional.

$\mathrm{Na}$ atualidade os ambientes e os próprios fluxos de informação não podem ser analisados considerando-se somente os planos do território, o arcabouço institucional das organizações e da cadeia produtiva em sua rede de relações. As dinâmicas de mercado em curso submetem o ambiente de negócios a novos planos de integração globalizadores e de ordem tecnológica desencadeando mudanças no quadro institucional, a fragilização dos contratos sociais e principalmente a redefinição das esferas de intervenção do Estado (GONZALEZ DE GOMEZ, 1999, p.28). Essas remodelações suscitam questões sobre a autonomia da informação produzida e que circula entre os atores sociais, questões como: diante desses imperativos globalizantes como é possível demarcar um contexto em que a informação tenha sentido? Como acontece a relação entre atores sociais que jogam diferentes jogos de informação? 
As questões acima formuladas indicam que a comunicação e a interação entre os atores nas diversas organizações são essenciais. A estrutura organizacional e os arranjos proporcionam níveis diferenciados de integração entre atores, sistemas e organizações. Quanto maior a estabilidade do ambiente maior a existência de fluxos uniformes de informação, dadas as possibilidades de integração e tendência à padronização de processos e procedimentos. As implicações territoriais (ambiente externo) e relacionadas à cultura organizacional (ambiente interno), esperando-se nesse segundo aspecto mais positivas, como também os recursos comunicativos em uso auxiliarão na dinâmica de circulação e apropriação de informações funcionais e importantes para a gestão e tomada de decisão nas organizações (VALENTIM, 2013). O seu contrário também é verdadeiro, a instabilidade do ambiente produz fluxos não uniformes e pouco assimiláveis. Os atravessamentos oriundos do ambiente externo, produzidos por dinâmicas não controláveis podem ser identificadas durante a gestão da informação como um recurso ampliado, uma força constitutiva para melhorar o reconhecimento desse ambiente e dos fatores que afetam a reprodução social da cadeia produtiva.

Observa-se finalmente que, do ponto de vista do mercado, quanto maior o desconhecimento dos modelos e práticas de gestão da informação maiores as dificuldades de aproximação e reconhecimento da informação como um valor para fortalecimento das atividades de negócio e inserção social da cadeia produtiva.

Sob o enfoque territorial tratamos não somente de ações de informação, mas de sistemas de ações de informação em contextos amplos. Propusemo-nos assim a desenvolver uma breve articulação teórica sob enfoque territorial dada a sua condição de espaço da ação, também de espelhamento do movimento, da singularidade, da dinâmica, das mutações e transformações em curso, modernizações e da explicitação dos fenômenos que, ao longo do tempo, se estabelecem entre os atores ou sujeitos sociais que o dinamizam sob antigas ou novas racionalidades, dependendo da trajetória.

\section{Referências}

AGUIAR, C. Minas e Espírito Santo: interação reforça debate sobre tecnologias para a sustentabilidade da cafeicultura. Portal Dia de Campo, 6 set. 2010. Disponível em: $<$ http://www.diadecampo.com.br/zpublisher/materias/Materia.asp?id=22610\&secao=Not \%EDcias>. Acesso em: 3 set. 2014.

ARAÚJO, V. M. R. H. de. A organização espacial da informação cientifica e tecnológica no Brasil. Ciência da Informação, Brasília, v. 14, n. 1, p. 17-24, jan. /jun. 1985. 
BALESTRIN, A.; VERSCHOORE, J. Redes de cooperação empresarial: estratégias de gestão na nova economia. Porto Alegre: Bookman, 2008.

CAFEICULTURA. Incaper em Revista, Vitória, v. 2/3, p. 22-23, jan. 2011/dez. 2012. Disponível em: $\quad$ http://www.incaper.es.gov.br/sistemas/uploads/files/ publicacoes/21184revistaincaper2012[1].pdf>. Acesso em: 3 ago. 2014.

CARVALHO, A. M. A. de. Novos enfoques no Campo da Ciência da Informação: uma discussão sobre a aplicabilidade do conceito de regime de informação em arranjos produtivos locais. Perspectivas em Ciência da Informação, Belo Horizonte, v. 14, n. especial, p. 213-227, 2009.

CHHOTRAY, V.; STOKER, G. Governance: theory and practice. New York: Palgrave Macmillan, 2009.

CHOO, C. W. A organização do conhecimento: como as organizações usam a informação para criar significado, construir conhecimento e tomar decisões. Trad. Eliana Rocha. 2. ed. São Paulo: Senac São Paulo, 2006.

CONAB. Superintendência de Informações do Agronegócio. Pesquisa de safras. Indicadores da Agropecuária, Brasília, v. 22, n. 7, p.13-23, jul. 2014. Disponível em: $<$ http://www.conab.gov.br/conab/Main.php? MagID=3\&MagNo=225>. Acesso em: 17 ago. 2014.

FONSECA, A. F. A. da et al. Jardins clonais, produção de sementes e mudas. In: FERRÃO, R. G. et al. (Editores). Café conilon. Vitória (ES): Incaper, 2007. Cap.8, p. 227-255.

GONZALEZ DE GOMEZ, M. N. O caráter seletivo das ações de informação. Informare, Rio de Janeiro, v. 5, n. 2, p. 7-31, 1999.

MONTE, E. Z. Exportações de café do Espírito Santo Aplicação da metodologia VAR. Revista de Política Agrícola, Brasília, v. 21, n. 4, p. 106-119, outubro/dezembro 2012. Disponível em: <https://seer.sede.embrapa.br/index.php/RPA/article/view/268>. Acesso em: 17 ago. 2014.

NONNENBERG, M. J. B.; REZENDE, G. C. de. Desenvolvimento da agropecuária do Espírito Santo. In: INSTITUTO JONES DOS SANTOS NEVES. Espírito Santo: instituições, desenvolvimento e inclusão social. Vitória: IJSN, 2010. Cap. 4, p. 139-163.

NORTH, D. C. Custos de transação, instituições e desempenho econômico. Rio de Janeiro: Instituto Liberal, 1994.

OLIVEIRA, L. R. de; BORGES, V. A. J. (Org.). Balanço Social 2013 Incaper. Vitória: Incaper, 2014.

REZENDE, A. M; ROSADO, P. L. A informação no mercado de café. In: ZAMBOLIM, L. (Ed.). Produção integrada de café. Viçosa: Universidade Federal de Viçosa, Departamento de Fitopatologia, 2003. Cap. 1, p. 1-46.

ROCHA, Haroldo Correa; MORANDI, Angela Maria. Cafeicultura e grande indústria: a transição no Espírito Santo 1955-1985. Vitória (ES): Fundação Ceciliano Abel de Almeida, 1991. 167p.

SANTOS, M. Técnica espaço tempo - Globalização e meio técnico-científico-Informacional. São Paulo, 1994. 
SILVA, E. S. da et al. Geração, difusão e transferência de tecnologia. In: FERRÃO, R. G. et al. (Editores). Café conilon. Vitória (ES): Incaper, 2007. Cap. 22, p. 547-621.

SILVA, M. Z. e. Espírito Santo: Estado, interesses e poder. Vitória: FCAA/SPDC, 1995.

SILVA, M. Z e. Trajetória político-institucional recente do Espírito Santo. In: INSTITUTO JONES DOS SANTOS NEVES. Espírito Santo: instituições, desenvolvimento e inclusão social. Vitória: IJSN, 2010. Cap. 1, p. 29-66.

SILVESTRE, L. Inovação na poda do café arábica. Portal Dia de Campo, 20 maio 2014. Disponível em: <http://www.diadecampo.com.br/zpublisher/ materias/Materia.asp?id=30212\&secao=Agrotemas $>$. Acesso em: 3 set. 2014.

VALENTIM, M. L. P. Ambientes e fluxos de informação. In: VALENTIM, M. L. P. (Org.). Ambientes e fluxos de informação. São Paulo: Cultura Acadêmica, 2010. Cap.1: p. 13-22.

VALENTIM, M. L. P. Ambientes e fluxos de informação em contextos empresariais: o caso do setor cárnico de Salamanca/Espanha. Brazilian Journal of Information Science, Marília, v. 7, n. especial, p. 299-323, 1. sem. 2013. Disponível em: <http://www2.marilia.Unesp.br/revistas/ index.php/bjis/index>. Acesso em:

VILLASCHI FILHO, A.; FELIPE, E. S. Políticas estaduais para arranjos produtivos locais no Espírito Santo: evolução e perspectivas. In: CAMPOS, R. R. et al. (Org.). Políticas estaduais para Arranjos Produtivos Locais no Sul, Sudeste e Centro-oeste do Brasil. Rio de Janeiro: E-papers, 2010. Cap. 8, p. 257-288.

ZYLBERSZTAJN, D. Estruturas de governança e coordenação do agribusiness: uma aplicação da nova economia das instituições. Tese de Livre Docência - FEA/USP. São Paulo, 1995.

ZYLBERSZTAJN, D. P\&D e a articulação do agribusiness. Revista de Administração, São Paulo, v. 28, n. 3, p. 73-78, julho/dezembro 1993.

Recebido/Recibido/Received: 2015-08-30 Aceitado/Aceptado/Accepted: 2015-10-22 